Kariyn Yamamoto, Arina Miki Kiyan, Jackeline Camargo Bagio, Kayque Araújo Borges Rossi, Francielle Delabio Berezuk and Márcio Eduardo Berezuk*

\title{
Green cyclic acetals production by glycerol etherification reaction with benzaldehyde using cationic acidic resin
}

https://doi.org/10.1515/gps-2018-0059

Received March 5, 2018; accepted August 29, 2018; previously published online October 25, 2018

\begin{abstract}
In this paper, we investigated the effect of temperature, glycerol etherification concentration with benzaldehyde, organic solvent and catalyst reuse effects using a cationic acidic resin as catalyst for production of green cyclic acetals of high commercial value. The best reaction conditions show a conversion above $93 \%$ of glycerol and yield to cyclic acetals above $61 \%$. The highest selectivity elements observed were 2-phenyl-1,3-dioxan-5-ol, in cis and trans isomer forms reaching $80 \%$. The temperature had a positive effect increasing on glycerol conversion, though it also favored the formation of undesired compounds. A high concentration of benzaldehyde reactant kept the selectivity values constant but increased glycerol conversion resulting in higher yields, mainly when organic solvents were used. Reuse of the catalyst resulted in a slight decrease in yield values, which demonstrated stability and durability of the catalyst used.
\end{abstract}

Keywords: acidic resin; benzaldehyde; cyclic acetals; etherification; glycerol.

\section{Introduction}

Considering all the biodiesel production chain, it is necessary to observe the glycerin formation, generated as a byproduct. The economic viability of glycerin has become an obstacle to its production. Thus, it was estimated that

\footnotetext{
*Corresponding author: Márcio Eduardo Berezuk, Federal Technological University of Paraná, Marcílio Dias St. 635, P0 86812460, Apucarana, Paraná, Brazil, e-mail: berezuk@utfpr.edu.br. https://orcid.org/0000-0002-6651-1351

Kariyn Yamamoto, Arina Miki Kiyan, Jackeline Camargo Bagio and Kayque Araújo Borges Rossi: Federal Technological University of Paraná, Marcílio Dias St. 635, P0 86812-460, Apucarana, Paraná, Brazil

Francielle Delabio Berezuk: Maringá State University, Colombo Av. 5790, PO 87020-900, Maringá, Paraná, Brazil
}

approximately $1 \mathrm{~kg}$ of crude glycerol is generated for every $10 \mathrm{~kg}$ of biodiesel produced [1, 2].

Glycerol (or glycerin) has great application in the cosmetics, personal hygiene, food, medicine and tobacco sectors. In terms of chemical transformation, it still presents limited applications, the main one being in explosives production, like nitroglycerin, and in the formation of alkyd resins [3].

In Brazil, the policy of using biodiesel as an alternative fuel to petrodiesel is conditioned by the blend rate between the two fuels, which is regulated by Ministry of Mines and Energy laws and supervised by its National Agency of Petroleum, Natural Gas and Biofuels. Actually, the blend value is $8 \%$ of biodiesel in petrodiesel (B8) and will increase to $10 \%$ in 2019 . According to the Brazilian Ministry of Development, Industry and Foreign Trade, Brazil produced approximately 380,000 tons of glycerin and exported 244,000 tons of crude glycerin and 60,000 tons of refined glycerin (glycerol), indicating internal consumption of glycerol of 76,000 tons [4]. This large production of glycerol must be destined to develop new chemical products to take advantage of its potential and to add economic production values.

One of the main transformation patterns of glycerol is the etherification reaction with alcohols, ketones or aldehydes, to promote formation of chemical compounds that present better commercial and economic value such as renewable fuels additives, surfactants, flavorings and solvents for use in medicine as well as anti-bacterial agents $[5,6]$.

Condensation reactions of glycerol with other alcohols produce glycerol ethers that may increase the burning properties of gasoline. Therefore, it may be considered a green additive to fuels. Researches show that glycerol acetals also aid improving blends with biodiesel [7].

Natural benzaldehyde has gained a space in industrial production as one of the most produced fragrances in the world and is obtained from natural compounds like cinnamon oil $[8,9]$. Glycerol acetalization with benzaldehyde is capable of producing green cyclic acetals such as 2-phenyl-1, 3-dioxan-5-ol or 2-phenyl-1,3-dioxolane-4-methanol 
(six- or five-ring atoms) which are seen as important reaction intermediates of the green platform for the production of dihydroxyacetone and 1,2-propanediol, of great commercial value $[10,11]$.

Scientific research indicates that acid catalysis promotes etherification reactions of glycerol, and the use of heterogeneous catalysis has been developed for chemical processes to have better separation stages and the possibility of reuse/catalysts regeneration [5]. Some research groups are using as catalysts ion exchange resins, zeolites, aluminosilicates, molecular sieves, acidic clays and mesoporous carbon, with modifications in their chemical structures being responsible for increasing the number of acidic sites [12-16].

In this work, glycerol etherification reactions with benzaldehyde were performed in order to form important cyclic acetals for the chemical industry, investigating the acidic cation exchange resin as a reaction catalyst. Parameters such as reaction temperature, reagent ratio, organic solvents and catalyst reuse were investigated to obtain valuable information on reaction conversion, selectivity and reaction yield.

\section{Materials and methods}

\subsection{Materials}

Glycerol (99\%, Synth Inc., Brazil), benzaldehyde (99\%, Vetec Chemical Inc., Brazil), methanol (99.5\%, Dinâmica Chemical Inc., Brazil), sodium chloride and sodium hydroxide (Vetec Chemical Inc., Brazil) are from an analytical standard used without prior treatment. Cationic acidic resin (IRA 120 Sigma-Aldrich, US) was pretreated in a forced circulation oven at $90^{\circ} \mathrm{C}$ for $2 \mathrm{~h}$ before being used as a reaction catalyst. Monoethylene glycol (99\%, Vetec Chemical Inc., Brazil) was used as an internal standard for gas chromatography (GC) analyses. Magnetic stirrer with heating control, $\mathrm{pH}$ meter and various glassware were also used.

\subsection{Products analysis}

Analysis of the reaction products utilized the Shimadzu QP-2010 Ultra gas chromatography with mass detector, using Rtx-Wax (Restek) column of $30 \mathrm{~m} \times 0.25 \mathrm{~mm} \times 0.25 \mu \mathrm{m}$. The temperature of the injector chamber was $250^{\circ} \mathrm{C}$, varying oven temperature from $40^{\circ} \mathrm{C}$ to $200^{\circ} \mathrm{C}$ with a rate of $10^{\circ} \mathrm{C} \cdot \mathrm{min}^{-1}$ with hold for $9 \mathrm{~min}$ in the final temperature. Split dilution was used at 1:60. External standards for GC analysis were used for quantification of glycerol and benzaldehyde. The monoethylene glycol was used as an internal standard diluted on methanol in the concentration of $100 \mathrm{mg} \cdot \mathrm{ml}^{-1}$, for quantification of the acetals products.

Glycerol conversion equation, as well as the selectivity for desired products and reaction yield, are defined by Equations (1) to (3) [17].
Conversion $(\%)=100 * \frac{\text { (initial mols reagent }- \text { final mols reagent })}{\text { initial mols reagent }}$

$$
\begin{aligned}
& \text { Selectivity }(\%)=100 * \frac{\text { desired mols product }}{\sum \text { all products mols }} \\
& \text { Yield }(\%)=\frac{\text { Conversion }(\%)^{\star} \text { selectivity }(\%)}{100}
\end{aligned}
$$

\subsection{Reactional experiments}

The experiment was conducted through etherification of glycerol with benzaldehyde in $50 \mathrm{ml}$ borosilicate glass batch reactors, with and without use of organic solvents. Moreover, to control the reaction solution, external-controlled hotplates with external thermostat and a magnetic stirring system were used. Besides that, the reactor was not attached to the reflux condenser in order to remove excess water from the reaction solution. Reactions with organic solvents needed to use reflux condenser.

2.3.1 Reactions without any solvent: No organic solvent was used in the first-stage etherification reactions. The reagents were added, and their quantities are specified in Table 1 . The use of $500 \mathrm{mg}$ of resin per test and the reaction time of $2 \mathrm{~h}$ was also fixed. We investigated three temperatures: $90^{\circ} \mathrm{C}, 110^{\circ} \mathrm{C}$ and $120^{\circ} \mathrm{C}$, and the ratio of glycerol to benzaldehyde varied at 1:1, 1:2 and 2:1. At the end of the reactions, an amount of material was filtered on qualitative filter papers (grade 4) with cotton, collected in $2 \mathrm{ml}$ vials and stored in a freezer. The experiments were performed in duplicate form. Catalyst amount used was chosen according to literature works $[6,10]$.

2.3.2 Reactions with organic solvent and catalyst reuse: Acetonitrile and dimethylsulfoxide (DMSO) were used in the etherification reactions aiming to verify some possible improvements in the reaction yield and behavior. Reuse of the acid resin was also tested. The temperature was fixed at $120^{\circ} \mathrm{C}$, time reaction was $2 \mathrm{~h}$, the quantities of all organic solvents were defined with $200 \mathrm{mmol}$ used for each reaction sample, and $270 \mathrm{mg}$ of resin was also used in proportional quantity with reagents and the reactions without solvent stage. Table 2 presents the quantities of the reagents used in

Table 1: Performed experiments without solvent use.

\begin{tabular}{lrrrr}
\hline Experiments $^{\mathbf{a}}$ & $\begin{array}{r}\text { Temperature } \\
\left({ }^{\circ} \mathrm{C}\right)\end{array}$ & $\begin{array}{r}\text { Ratio } \\
\text { Gly/Bz }\end{array}$ & & \multicolumn{2}{c}{ Quantity (mmol) } \\
\cline { 3 - 5 } & & & Glycerol & Benzaldehyde \\
\hline 1 & & $1: 1$ & 55 & 55 \\
2 & 90 & $1: 2$ & 55 & 110 \\
3 & & $2: 1$ & 110 & 55 \\
4 & 110 & $1: 1$ & 55 & 55 \\
5 & & $1: 2$ & 55 & 110 \\
6 & & $2: 1$ & 110 & 55 \\
7 & 120 & $1: 1$ & 55 & 55 \\
8 & & $1: 2$ & 55 & 110 \\
9 & & $2: 1$ & 110 & 55 \\
\hline
\end{tabular}

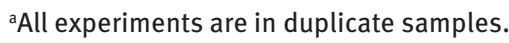


Table 2: Performed experiments with organic solvents and catalyst reuse.

\begin{tabular}{lrrr}
\hline Experiments $^{\text {a }}$ & Ratio Gly/Bz & \multicolumn{2}{c}{ Quantity (mmol) } \\
\cline { 3 - 4 } & & Glycerol & Benzaldehyde \\
\hline 10 & $1: 1$ & 30 & 30 \\
11 & $1: 2$ & 30 & 60 \\
12 & $2: 1$ & 60 & 30 \\
13 & $1: 1$ & 30 & 30 \\
14 & $1: 2$ & 30 & 60 \\
15 & $2: 1$ & 60 & 30 \\
16 & $1: 1$ & 30 & 30 \\
17 & $1: 2$ & 30 & 60 \\
18 & $2: 1$ & 60 & 30 \\
Reuse experiments & & & 30 \\
19 & $1: 1$ & 30 & 30 \\
20 & $1: 2$ & 30 & 60 \\
21 & $2: 1$ & 60 & \\
\hline
\end{tabular}

${ }^{\mathrm{a} A l l}$ experiments are in duplicate samples.

the experiments of this section. In the reuse experiments, catalysts were separated by simple filtration with qualitative paper (grade 4) and cotton, washed with distilled water, dried in forced circulation oven at $90^{\circ} \mathrm{C}$ for $2 \mathrm{~h}$ and then collected.

Scheme 1 presents the glycerol etherification reaction with benzaldehyde to obtain the main products according to the present work.

\subsection{Acid exchange resin}

The amount of Brönsted acid sites of the catalysts was estimated by an acid-base titration technique. About $0.2 \mathrm{~g}$ of catalyst was weighed and immersed in $20 \mathrm{ml}$ of $3 \mathrm{M}$ sodium chloride $(\mathrm{NaCl})$ solution under stirring for $30 \mathrm{~h}$. During this period, ion exchange occurred between the $\mathrm{H}^{+}$of the catalyst surface and the $\mathrm{Na}^{+}$in the solution. Afterward the mixture was filtered, and the titrated solution was treated with $1 \mathrm{~m}$ sodium hydroxide solution and monitored by a $\mathrm{pH}$ meter. Phenolphthalein indicator was used. Titration endpoint was determined when the $\mathrm{pH}$ reached neutrality $[13,18]$.

The cation exchange resin employed had a density of acidic sites of $1671 \pm 26 \mu \mathrm{mol} / \mathrm{g}$. It means that it has important acid characteristics for application as the catalyst in etherification reactions.

\section{Results and discussion}

Glycerol etherification with benzaldehyde may form desired cyclic acetals as well as other open-chain acetals. We considered the formation of cis/trans-2-phenyl-1,3dioxan-5-ol (cyclic six-membered atoms) and 2-phenyl1,3-dioxolane (cyclic five-membered atoms) as desired major products (cyclic acetals). Besides that, the formation of methyl-3-hydroxy-3-phenylpropanoate (non-cyclic acetal), benzoic acid and other minor products was also observed.<smiles>COC(=O)Cc1ccccc1CC(O)C(=O)OC</smiles>

Scheme 1: Main products observed in the glycerol etherification reaction with benzaldehyde. 
From Figures 1 and 2, glycerol conversion and reaction yield in the formation of the desired cyclic products were observed. At this stage, the time and quantity of catalyst used was fixed at $2 \mathrm{~h}$ and $500 \mathrm{mg}$, varying the temperature and the stoichiometry of the reactants. Reactions were performed without use of organic solvent.

Etherification reactions of glycerol with benzaldehyde had temperature-dependent behavior. The increase in temperature favored gain in glycerol conversion, both in the limiting and in excess reagent condition. Comparing the glycerol conversion results in the stoichiometric ratio and in the situation containing excess benzaldehyde, it was observed that the reaction with excess benzaldehyde favored the conversion of glycerol (Gly/Bz ratio 1:2),

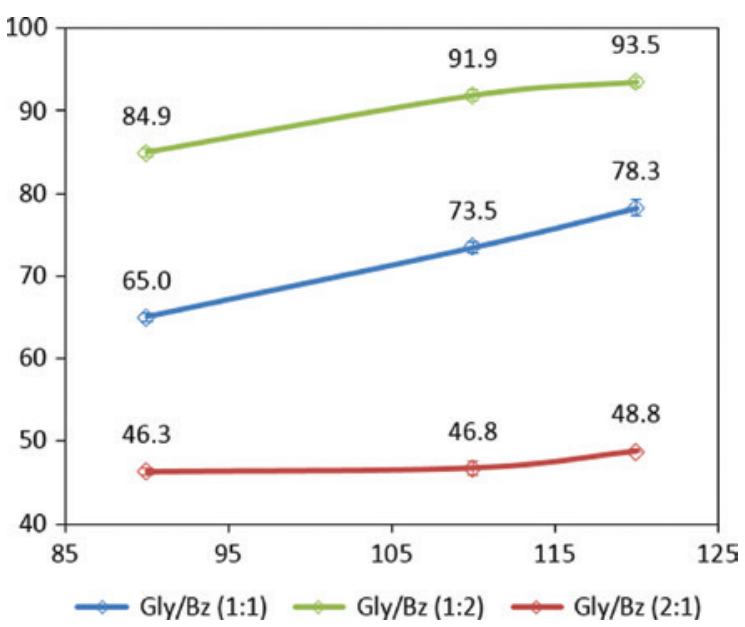

Figure 1: Glycerol conversion (\%) versus different temperatures $\left({ }^{\circ} \mathrm{C}\right)$ and reagents ratios.

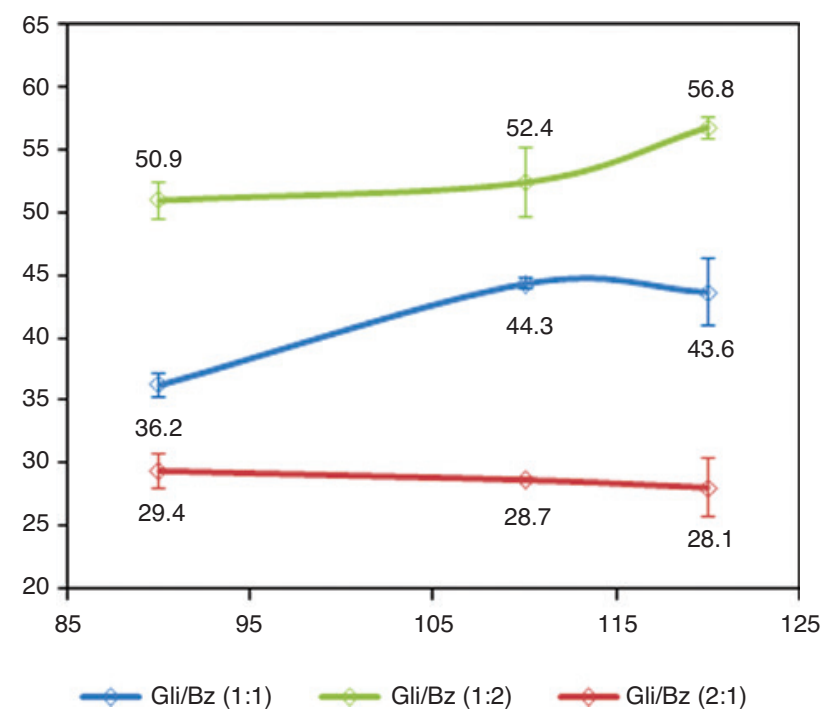

Figure 2: Reaction yields $(\%)$ versus different temperatures $\left({ }^{\circ} \mathrm{C}\right)$ and reagents ratios. probably altering the equilibrium of reaction in the formation of their products. These results were reached at all observed temperatures. However, the difference between the values obtained is more evident at the temperature of $90^{\circ} \mathrm{C}$. At $120^{\circ} \mathrm{C}$, the maximum glycerol conversion reached $93.5 \%$ with reaction yield up to $56.8 \%$. At this point, glycerol conversion reached $93.5 \%$.

In a similar work, Silva and co-workers [19] investigated etherification of glycerol with several C4 to C10 open-chain aldehydes and observed conversions of $17-75 \%$ with the use of butanal in a 2-h reaction with 1:1.05 ratio of glycerol/aldehyde at temperature of $70^{\circ} \mathrm{C}$, using DMSO as the reaction solvent. The results presented are close to the values contained in Figure 2, indicating that the use of benzaldehyde is also capable of forming acetals and, in our work, cyclic acetals.

Deutsch and co-workers [10] used several catalysts such as acid zeolites, cation exchange resins and acidic clays obtaining yields of up to $94 \%$ in cyclic acetals by etherification of glycerol with benzaldehyde, removing the water from the reaction medium during the reactions. According to the authors, the presence of water (reaction product) contributes greatly to the reduction of reaction yield. In our work, it was not possible to remove the water completely, indicating that the reactions could have higher yields than those observed.

Rodrigues and co-workers [20-23] investigated the role of mass transfer and the adsorption of the reactant molecules on the reaction of ethanol with acetaldehyde and glycerol with acetaldehyde for the formation of ethylacetals or glycerol ethyl acetals. According to the authors, the effects of mass transfer represented by the reactants' solubility and diffusivity of the elements on the catalytic surface are important factors for the reaction yield increase and, consequently, the reaction kinetics.

In our work, high values of glycerol conversion and yield in the desired products may indicate that the diffusive aspect of the glycerol in the reaction medium as well as the surface of the cation resin contribute to the dynamics of the reaction. However, this fact did not present a behavior that has great influence in the experimental conditions observed due to the high results obtained in the conversion of glycerol. Certainly, this fact needs further investigation.

In Figure $3 \mathrm{~A}-\mathrm{C}$ we observe that there was a higher selectivity of products besides cyclic acetals for most temperatures and reagent concentration conditions analyzed, indicating that the acid cationic resin used demonstrated efficient production of acetals 2-phenyl-1,3-dioxan-5-ol in cis and trans isomers and 2-phenyl-1,3-dioxolane. Selectivity values reached $57.0-63.5 \%$ for cyclic acetals. 

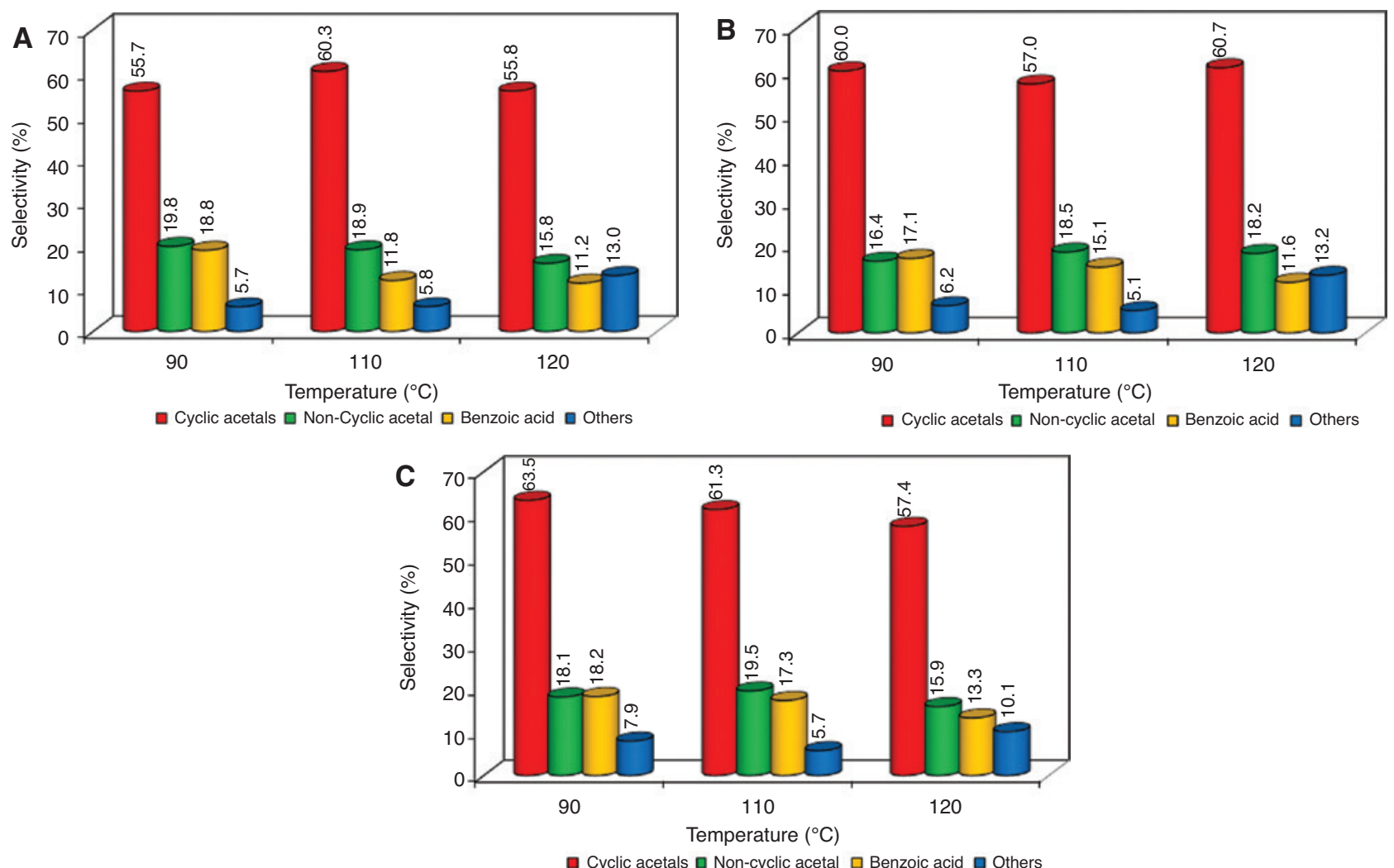

Figure 3: Selectivity $(\%)$ comparison ratios versus temperature $\left({ }^{\circ} \mathrm{C}\right)$ about the main products of the glycerol etherification with benzaldehyde. (A) Gly/Bz ratio (1:1), (B) Gly/Bz ratio (1:2), and (C) Gly/Bz ratio (2:1). Errors deviation in 0.5-1.0\%.

All concentration ratios observed between glycerol and benzaldehyde had no significant differences in selectivity behavior to cyclic and non-cyclic acetals products. The increase in temperature favored the formation the other non-desired products, but this increase was small, reaching only $13 \%$. However, the increase in temperature resulted in a significant decrease in the formation of benzoic acid (from $18.8 \%$ to $11.2 \%$ ), a behavior contrary to that observed in the formation of other non-desired reaction products. It is possible that the benzoic acid has been transformed into subsequent reaction products with the reaction temperature gain.

\subsection{Use of organic solvent effects}

Acetonitrile and DMSO were applied in the etherification reactions to investigate the behavior with the use of these solvents in the reaction medium. The quantities of reagents are shown in Table 2. Reactions without the use of resin catalyst were also performed and named "Blank".

In Figure 4, in general terms, the use of acetonitrile showed greater gains in the conversion of glycerol compared to the use of DMSO, considering all the glycerol/

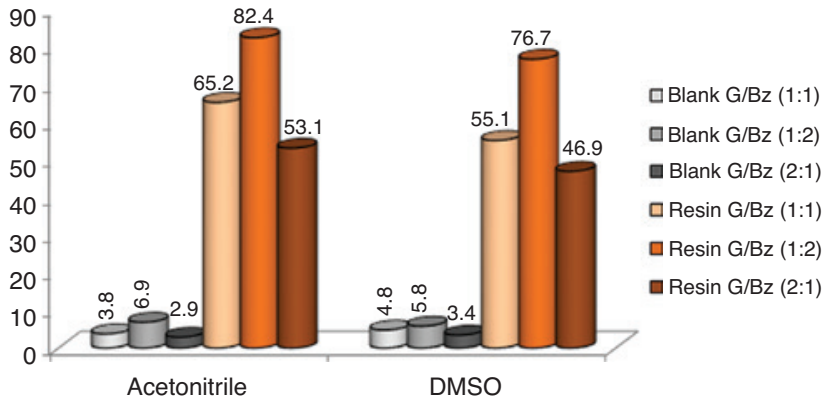

Figure 4: Glycerol conversion (\%) comparison ratios versus organic solvents. Errors deviation in $1.0-1.8 \%$.

benzaldehyde ratios. The best values reached $82.4 \%$ of conversion. However, these results are less expressive when compared to reaction without use of organic solvents (Figure 2). It can be deduced that the possible difficulties of diffusion and mass transfer reactions without solvents could have been minimized due to the temperature, stirring and solubility conditions between the reactants. Dilution did not demonstrate a different effect to improve glycerol conversion values. Regarding glycerol/ benzaldehyde ratios, excess of benzaldehyde boosted glycerol conversion. 


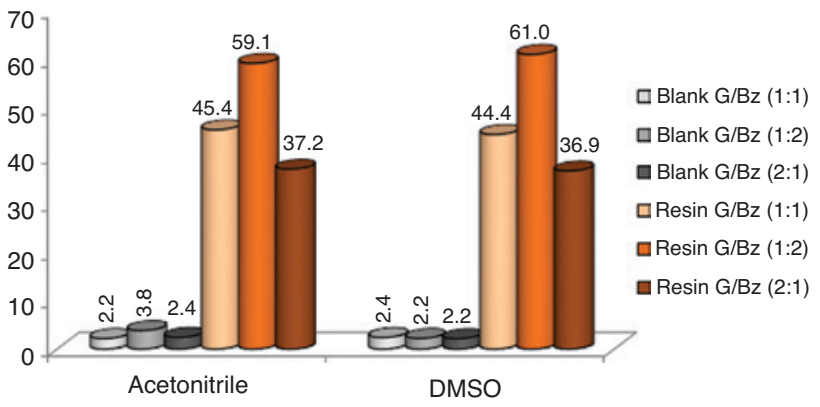

Figure 5: Glycerol yield (\%) comparison ratios versus organic solvents. Errors deviation in 1.0-2.0\%.

Figures 5 and $6 \mathrm{~A}-\mathrm{C}$ present profiles of glycerol yield and selectivity for the desired products. The use of organic solvents increased the selectivity for cyclic acetals reaching up to $80.9 \%$. DMSO showed better results compared to acetonitrile with a difference of up to $10 \%$. This selectivity behavior is responsible for the reaction yield results where both solvents used provide similar results in all conditions analyzed. Again, the reactions containing an excess of reagent benzaldehyde present higher reaction yield. Reactions with the use of acetonitrile promoted more activity reaction medium than the DMSO solvent did; nevertheless, DMSO promoted more selectivity medium for the desired products resulting in a compensation effect of the reaction yield.

\subsection{Effects of catalyst reuse}

Reuse of the acidic resin was conducted in the experiments to identify characteristics of catalyst durability in the reaction and is presented in Figure 7.

After three reaction times, glycerol conversion had a slight decrease in all glycerol/benzaldehyde ratios which shows good catalytic stability, especially in benzaldehyde excess concentration, ranging $84.1-77.8 \%$. No significant differences should be observed with respect to selectivity values about formation of cyclic acetals, and values obtained were close to $70 \%$. Consequently, yield behavior is the same as conversion behavior, and best values ranged between $59.1 \%$ and $55.1 \%$.

After three-times catalyst reuse, acid-base titration was conducted again to determine new acidic site density, and values of $1432 \pm 37 \mu \mathrm{mol} / \mathrm{g}$ were observed. This reduction represents $14.3 \%$ compared to the fresh acidic values and is expected; however, it is consistent with the decrease

\section{A}

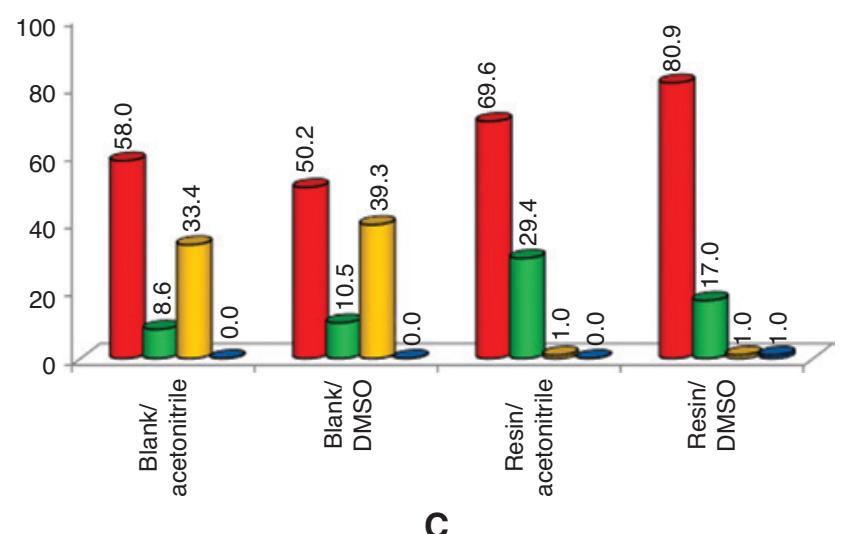

B

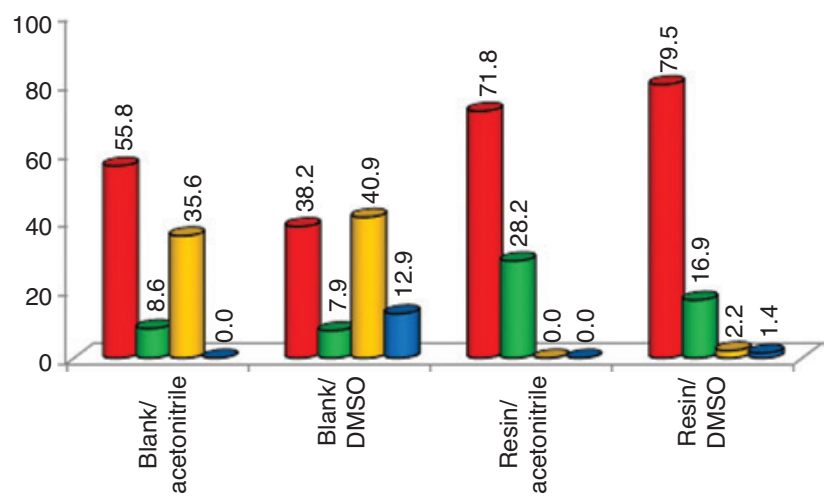

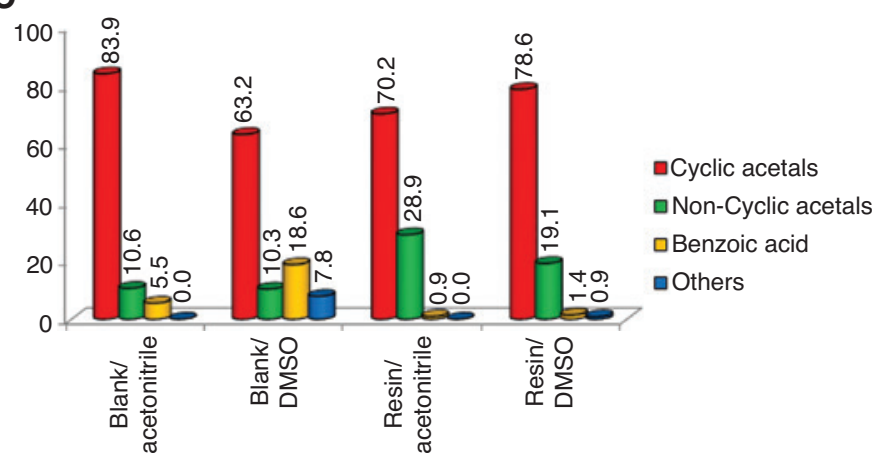

Figure 6: Selectivity (\%) comparison ratios versus organic solvents about the main products of the glycerol etherification with benzaldehyde. (A) Gly/Bz ratio (1:1), (B) Gly/Bz ratio (1:2), and (C) Gly/Bz ratio (2:1). Errors deviation in 0.7-2.5\%. 


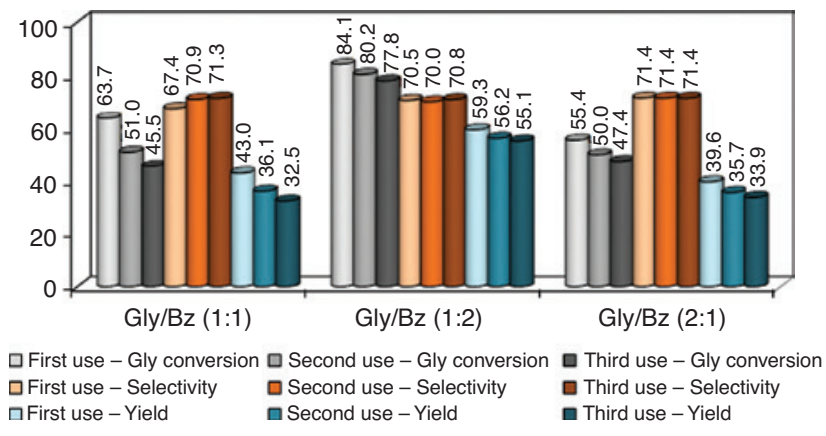

Figure 7: Catalyst reuse experiments stats (\%) versus glycerol/ benzaldehyde comparison ratios. Glycerol conversion in shades of gray, cyclic acetals selectivity in shades of red and reaction yield in shades of blue. Errors deviation in $0.5-1.5 \%$.

in values of conversion and yield observed. This behavior brings safety and durability to the resin application in glycerol etherification reactions for industrial applicability.

\subsection{Reaction pathway}

Sudarsanam and co-workers [11] also studied etherification reactions between glycerol and benzaldehyde and presented a possible reaction pathway. The formation of a positively charged carbonyl carbon of the benzaldehyde added with a strong interaction between the oxygen atoms of the carbonyl group and the solid acid catalyst occurs in the first steps of the surface reaction. Afterward, the oxygen atom of the glycerol attacks the positively charged carbonyl carbon forming the benzyl cation, an intermediate product. In the follow step, two isomeric cyclic acetals, namely, [A] 2-phenyl-1,3-dioxan-5-ol and 2-phenyl-1,3-dioxolane-4-methanol appears through different routes, respectively. The formation of the cyclic compound [B] 2-phenyl-1,3-dioxolane is more complex, which may indicate its less formation in the reaction medium. Following the formation of a reaction intermediate, 2-phenyl-1,3-dioxolane-4-methanol is formed which, in the presence of water and benzaldehyde, could form 2-phenyl-1,3-dioxolane as well as benzoic acid and methanol.

In addition to that, a non-cyclic acetal, namely, [C] methyl-3-hydroxy-3-phenylpropanoate, was formed with another glycerol oxygen attack with water formation [14]. Formation of [D] benzoic acid could occur with hydrolysis reaction or a redox disproportionation of benzaldehyde to carboxylic acids and alcohols called the Cannizzaro

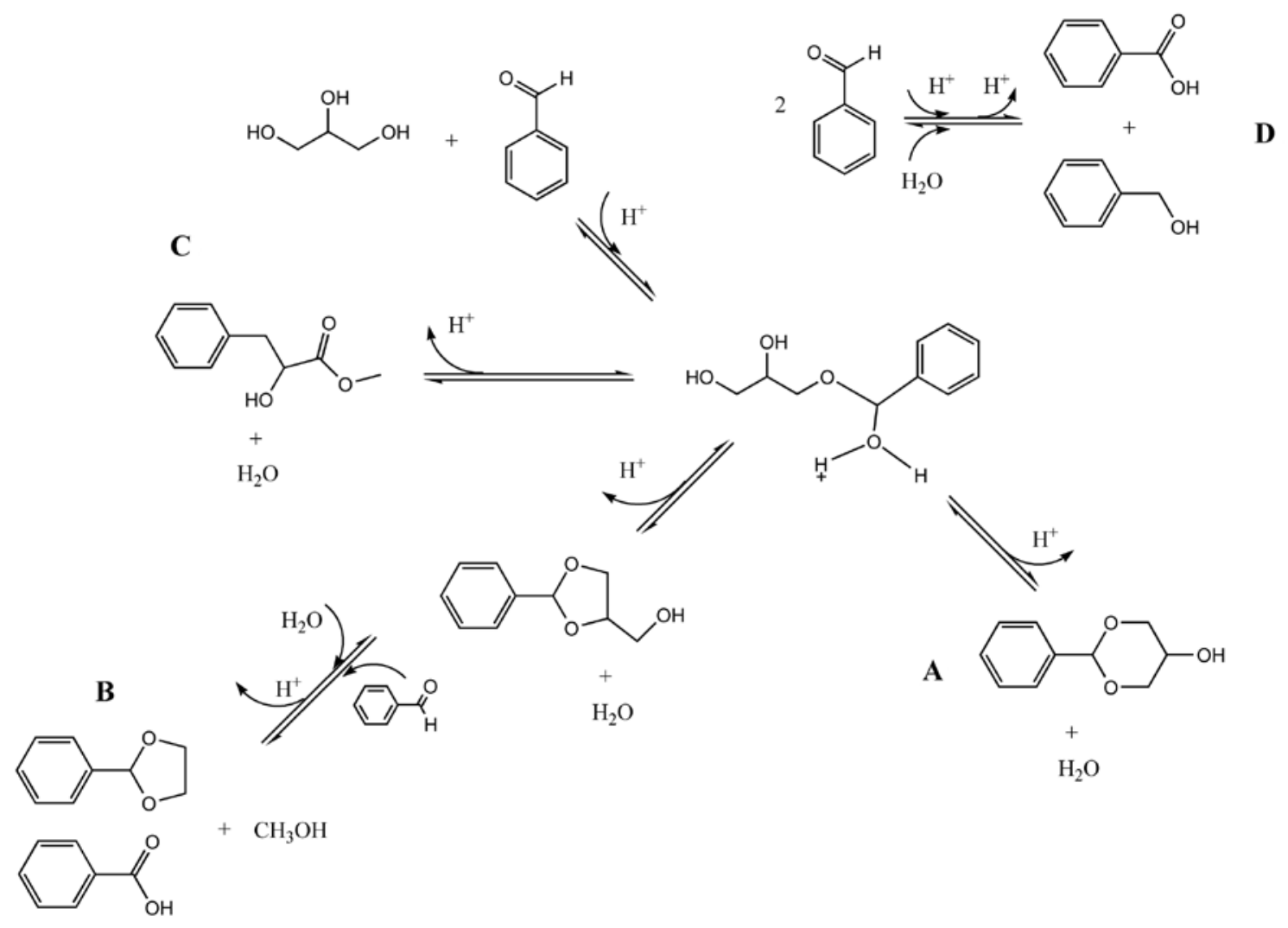

Scheme 2: Possible reaction mechanism for the glycerol etherification with benzaldehyde. (A) Cis/trans-2-phenyl-1.3-dioxan-5-ol, (B) 2-phenyl-1.3-dioxolane, (C) methyl-3-hidroxy-3-phenylpropanoate, and (D) benzoic acid and benzyl alcohol. 
reaction [24]. Scheme 2 presents the reaction pathway observed.

\section{Conclusions}

Cyclic acetals of high commercial value were produced through glycerol etherification with benzaldehyde using a cationic acidic resin, with and without the use of organic solvents as reaction medium. 2-Phenyl-1,3-dioxan-5-ol compounds in cis and trans isomers were the major cyclic acetals formed in the reaction, achieving conversions of $93 \%$, selectivity above $80 \%$ and better yields around $61 \%$.

Temperature had a positive effect on glycerol conversion; however, it also favored the formation of undesired compounds, mainly caused by high reactivity of benzaldehyde with glycerol, forming benzoic acid and other second undesired products. On the other hand, the ratios of reagents, richer in glycerol or benzaldehyde, were important to verify the shift in selectivity behavior of desired compounds. Benzaldehyde-rich configuration forced a greater glycerol conversion above 93\% with no significant selective decrease equalizing the selectivity effect and giving a final yield above $56.8 \%$ to 2-phenyl-1,3-dioxan-5-ol.

Reactions with the use of organic solvents increase the selectivity for cyclic acetals reaching 80.9\% responsible for increasing reaction yield up to $59-61 \%$. Reactions in three-time catalyst reuse presented a slight decrease on glycerol conversion with no significant effect in selectivity values, which resulted in a small decrease; values of reaction yield ranged between 59\% and 55\%.

Acknowledgements: We are grateful to UTFPR - Campus Apucarana, DEQ/UEM and Fundação Araucária for financial support.

\section{References}

[1] Zheng Y, Chen X, Shen Y. Chem. Rev. 2008, 108, 5253-5277.
[2] Okoye PU, Hammed BH. Renew. Sust. Energ. Rev. 2016, 53, 558-574.

[3] Mota CJA, Silva CXA, Gonçalves VLC. Quím. Nova 2009, 32, 639-648.

[4] EPE, Empresa de Pesquisa Energética. Análise de conjuntura dos biocombustíveis. Available at http://epe.gov.br/sites-pt/ publicacoes-dados-abertos/publicacoes/PublicacoesArquivos/ publicacao-167/Analise_de_Conjuntura_dos_BiocombustiveisAno_2017.pdf. Accessed in May 2018.

[5] Gu Y, Azzouri A, Pouilloux Y, Jérôme F, Barrault J. Green Chem. 2008, 10, 164-167.

[6] Silva CRB, Gonçalves VLC, Lachter ER, Mota CJA. J. Braz. Chem. Soc. 2009, 20, 201-204.

[7] Garcia R, Besson M, Gallezot P. Appl. Catal. A: Gen. 1995, 127, 165-176.

[8] Chen H, Ji H, Zhou X, Wang L. Tetrahedron 2010, 66, 9888-9893.

[9] Passos ML, Ribeiro CP. Innovation in Food Engineering: New Techniques and Products, CRC Press: Boca Raton, 2010.

[10] Deutsch J, Martin A, Lieske H. J. Catal. 2007, 245, 428-435.

[11] Sudarsanam P, Mallesham B, Prasad AN, Reddy PS, Reddy BM. Fuel Process. Technol. 2013, 106, 539-545.

[12] Melero JA, Vicente G, Paniagua M, Morales G, Muñoz P. Bioresour. Technol. 2012, 103, 142-151.

[13] Pico MP, Rodríguez S, Santos A, Romero A. Ind. Eng. Chem. Res. 2013, 52, 14545-14555.

[14] Silva CXA, Gonçalves VLC, Mota CJA. Green Chem. 2009, 11, 38-41.

[15] Khayoon MS, Hameed BH. Appl. Catal. A: Gen. 2013, 464-465, 191-199.

[16] Khayoon MS, Hameed BH. Bioresour. Technol. 2010, 101, 6225-6229.

[17] Missen RW, Mins CA, Saville BA. Introduction to Chemical Reaction Engineering and Kinetics, John Wiley \& Sons: New York, 1999.

[18] López DE, Goodwin JG, Jr., Bruce DA. J. Catal. 2007, 245, 381-391.

[19] Silva PHR, Gonçalves VLC, Mota CJA. Bioresour. Technol. 2010, 101, 6225-6229.

[20] Silva VMTM, Rodrigues AE. Chem. Eng. Sci. 2006, 61, 316-331.

[21] Silva VMTM, Rodrigues AE. Chem. Eng. Sci. 2001, 56, 1255-1263.

[22] Faria RPV, Pereira CSM, Silva VMTM, Loureiro JM, Rodrigues AE. Chem. Eng. J. 2014, 258, 229-239.

[23] Faria RPV, Pereira CSM, Silva VMTM, Loureiro JM, Rodrigues AE. Chem. Eng. J. 2013, 233, 159-167.

[24] Kikhtyanin O, Lesnik E, Kubička D. Appl. Catal. A: Gen. 2016, 525, 215-225. 